\title{
CORRELATES AND PREDICTORS OF SELF-ASSESSMENTS OF HEALTH AND PHYSICAL FITNESS AMONG FEMALE PARTICIPANTS OF UNIVERSITY OF THE THIRD AGE CLASSES
}

\author{
BARTŁOMIEJ KRYNICKIIA, MONIKA GUSZKOWSKA², EWA KOZDROŃ1A, EWA NIEDZIELSKAIA, \\ JOANNA PIOTROWSKA'A, ANNA LEŚ1B
}
IJózef Pitsudski University of Physical Education in Warsaw, Faculty of Tourism and Recreation, Department of Methodology of Recreation ${ }^{a}$, Department of Theory of Recreation ${ }^{b}$, Warsaw, Poland
2Józef Piłsudski University of Physical Education in Warsaw, Faculty of Rehabilitation, Department of Clinical Psychology and Special Needs Education, Warsaw, Poland
Mailing address: Bartłomiej Krynicki, Józef Piłsudski University of Physical Education in Warsaw, Faculty of Tourism and Recreation, 34 Marymoncka Street, 00-986 Warsaw, tel.: +48 22 8340431, fax: +48 22 8651080, e-mail: bartekkrynicki@poczta.onet.pl

\begin{abstract}
Introduction. We tested how female University of the Third Age (U3A) attendees evaluated their health, physical fitness, and satisfaction with health. We also examined various factors potentially underlying those self-assessments, that is objective indicators of health and physical fitness, their potential determinants (age and financial situation), and potential modifiers of self-assessment (mood, perceptive ability, and education). Material and methods. A total of 116 female participants attending U3A classes in Warsaw aged 50-88 years evaluated their health and fitness on a 100-level visual scale and their satisfaction with their health on a five-level Likert scale. Each participant completed the UWIST mood adjective checklist (UMACL) by Matthews, Chamberlain, and Jones and Yesavage's geriatric depression scale, underwent the Fullerton fitness test, a hand grip strength test, Romberg's test, and Ciechanowicz and Stanczyk's attention and perception test, as well as filling out a specially designed questionnaire. Results. Self-assessments of health were found to correlate with aggravated symptoms of depression and certain components of physical fitness, but not with age or financial situation. Self-assessments of physical fitness, in turn, were strongly correlated with objective indicators of physical health and depression and less strongly with dexterity test results. General satisfaction levels, in turn, were found to be associated with long-term conditions, aggravated symptoms of depression, and financial situation. Conclusions. Overall, our results confirm that self-assessments are a moderately accurate indicator of the general health and physical fitness of elderly people: they correlated to a certain degree with more objective indicators of health/fitness but were influenced by modifying factors, particularly cognitive ones.
\end{abstract}

Key words: elderly people, cognitive ability, physical activity, depression

\section{Introduction}

Increasing average lifespans, combined with gradually falling birth rates, mean that societies are ageing rapidly. This is especially notable in highly-developed countries [1] and extends to Poland. The traditional model of the family is also shifting, with younger generations more and more rarely providing security, love, and a sense of belonging to older people [2]. Instead, growing numbers of seniors are living out their later years alone [3], increasingly having to take responsibility for their healthcare; they also need to remain independently mobile (a fundamental indicator of health) frequently into their advanced years.

Recent studies have shown that biological ageing is not the only determinant that may underlie the deterioration of an individual's health and mobility. According to the dynamic life model, a person's health potential in old age instead depends on a range of variables, rooted in earlier stages of their life. Conditions found to be conducive to good ageing include having a high level of education, remaining married, enjoying a good financial situation, having a positive assessment of one's health, maintaining physical fitness, and having a healthy weight and diet [4]. The interactions between such factors influence a person's overall self-assessment of their ageing process. The results of many studies suggest that physical fitness is an important moderator here [5]. This gives rise to a need for further in-depth research into the complex relationships between age, physical activity, and health, which may serve as a basis for proposing preventive guidelines concerning lifestyle in its broadest sense [6].

The relationship between physical activity and health goes both ways. On one hand, physical activity depends on health: the healthier an individual is (objectively and subjectively), the more potentially mobile they are, which provides them with more opportunities for being active. On the other, physical activity has a direct effect on the health of an individual and their self-assessment of their quality of life. Maintaining a sufficient level of physical activity optimises adaptive, morphological, and functional mechanisms. People who are more physically active generally perceive their health as better than those who do not engage in physical activity $[1,8,9]$. Older people who engage in physical activity assess their quality of life in physical terms (in- 
cluding independence and functioning in their environment) more positively than those who do not [10].

Self-assessment of health naturally decreases with age $[6,11$, $12,13,14]$, which is of course linked with an objective worsening of health and reduced biological resources of the body. It has also been found to be correlated with education and financial situation $[6,12,13,14]$. Links between self-assessment of health and financial situation are generally explained in terms of the fact that people who are financially better off are able to take better care of themselves and have better access to healthy food, medical care, etc. The link with education is interpreted either as being related to financial situation or to an increased awareness of health in people who are more highly educated. Selfassessment of health is also known to be associated with more objective indicators, such as the presence of chronic illnesses, aggravated symptoms, and seeking medical advice, the relationships being moderately strong $[11,13]$.

When interpreting the results of studies like those described above, we should bear in mind the limitations of using subjective indicators of health, since they of course describe how individuals perceive and describe their health rather than what condition their health is objectively in. As such, self-assessments of health may be affected by a range of factors, the leading kind of which in elderly people relates to cognitive ability. Since perception ability deteriorates with age, information reaching the brain from the environment grows more limited in its scope and less detailed. Reduced memory processes result in poorer recollection of events [15], which impacts the ability to make self-assessments. An individual's emotional state at the time of evaluation is also relevant, as is their long-term mood. Negative affect can result in the prioritisation of negative information, making it easier to notice and remember [16, 17]. As a result, self-assessments of health and/or physical fitness by individuals experiencing negative emotions are lower. Moreover, it is likely that such modifiers have a stronger impact on assessing satisfaction with one's health than on assessing its actual level.

Comparing and juxtaposing the results of health selfassessments against both potential modifying factors and more objective health indicators can provide greater insight into the extent to which these various factors and indicators contribute to health self-assessments. The same can be said for selfevaluations of physical fitness, in particular when objective indicators are available, and it seems justified to preliminarily assume that the same factors modifying self-assessments of health also influence self-assessments of physical fitness [5].

The aim of the analysis presented here, therefore, was to test how women attending lectures at the U3A at the University of Physical Education in Warsaw evaluated their health, physical fitness, and satisfaction with health, and to look for correlations with factors of several types, that is factors related to the aspects being self-assessed (i.e. objective indicators of health and physical fitness), potential determinants of health and physical fitness (age and financial situation), and potential modifiers of self-assessment (mood, perceptive ability, and education). Overall, the aim of the study was to gain more insight into the extent to which self-assessment is a reliable indicator of general health and physical fitness in elderly people.

\section{Material and methods}

The participants of the project were 116 women aged between 50 and $88(\mathrm{M}=68.17$; $\mathrm{SD}=6.395)$ attending U3A lectures at the University of Physical Education in Warsaw. The majority of participants had tertiary education (58.8\%), 40\% had sec- ondary education, and only $1.3 \%$ had primary education. As for their marital status, $46.8 \%$ were married, $29.9 \%$ were widowed, $16.9 \%$ were divorced, and $6.5 \%$ were single. Almost half lived alone $(45.4 \%)$ and almost as many (44.2\%) lived with their husbands, with the remaining $10.4 \%$ living with other family members. Thirty-nine percent described their financial situation as average, $37.7 \%$ as comfortable, $10.4 \%$ as either very comfortable or bad, and only $2.6 \%$ as very bad. Two-thirds of participants $(67.1 \%)$ had chronic health conditions, and $83.1 \%$ took regular medication.

The participants assessed their health and physical fitness on a 100-level visual "thermometer" scale. They were asked to evaluate their health and physical fitness on the day of the study. Their satisfaction with their health, in turn, was taken as the answer to the second question in the WHOQOL-BREF questionnaire ("Are you satisfied with your health?"), which used a fivepoint scale (from 1 - "very unsatisfied" to 5 - "very satisfied") and was completed in reference to the period of four weeks preceding the study.

Answers to the questionnaire concerning chronic illnesses and regular medication use, and the 15-point Yesavage geriatric depression scale [18] were regarded as more accurate indicators of health. The Yesavage scale is based on 15 statements describing the basic symptoms of depression. Respondents give "yes/ no" answers with respect to whether or not they had experienced particular symptoms in the two weeks prior to the study.

The Fullerton fitness test was used as an objective indicator of physical fitness. The test included the following six exercises:

1. arm curl, assessing upper body strength;

2. 30-second chair stand, assessing lower body strength;

3. back scratch test, assessing upper body mobility;

4. chair sit-and-reach test, assessing lower body flexibility (hamstrings in particular);

5. eight foot up-and-go and six-minute walk, assessing agility (dynamic balance) and aerobic endurance;

6. two-minute step-in-place test, assessing aerobic endurance when the six-minute walk was not possible.

We also conducted the hand grip test using a dynamometer and the Romberg test with eyes closed and open, assessing static balance.

In order to assess perception, regarded as a modifier of selfassessment, we used the attention and perception test (version 6/9) devised by Ciechanowicz and Stańczak [19], providing information on perception speed (number of symbols processed), reliability (number of wrong answers), and attention (number of omissions). The participants were allowed the standard length of time (three minutes) to complete the tests.

In order to assess the other modifying factor (mood), we used the UWIST mood adjective checklist (UMACL) by Matthews, Chamberlain, and Jones [16], adapted for Poland by Goryńska [20], comprising 29 items (adjectives) forming three scales: tense arousal (nine items), energetic arousal (ten items), and hedonic tone (ten items). The participants were asked to complete the questionnaire in reference to their mood during the week preceding the study.

Additionally, information on the participants' age, education, and financial situation was collected using a questionnaire devised for the study.

\section{Results}

Participants assessed their health and physical fitness on a 1-100 visual scale, with the results ranging between 20 and 100. The mean results were $77.40( \pm 13.20)$ and $79.15( \pm 14.62)$, 
respectively. Mean satisfaction with health, evaluated on a 1-5 scale, was $3.61( \pm 0.72)$. Two-thirds of participants $(67.2 \%)$ described themselves as satisfied with their health, with just over a fifth (21.9\%) being ambivalent ("neither satisfied nor dissatisfied"). The other answers were given far less frequently ("dissatisfied" - 7.3\%, "very dissatisfied" - 1.5\%, and "very satisfied" $2.2 \%)$.

We used Pearson's linear correlation coefficient (r) to seek relationships between the variables. Due to the relatively small sample size, we also considered relationships on the tendency level. Self-assessment of health was found to be positively correlated with self-assessment of physical fitness $(r=0.694)$ and satisfaction with health $(r=0.320)$, whereas satisfaction with health was directly proportional to self-assessment of physical fitness $(r=0.396)$. All these correlations were significant on the $\mathrm{p}<0.001$ level.

Table 1 shows the results of the correlation coefficients between various pairs of variables: self-assessments of health, physical fitness, and satisfaction with health, on the one hand, and various objective indicators of health and physical fitness on the other. Self-assessments of health and physical fitness were both found to be strongly correlated with regular medication use, chronic illnesses, and indicators of depression, whereas satisfaction with health was found to be strongly correlated with the latter two. Notably, self-assessment of physical fitness was found to be more closely correlated with factors seen as indictors assessing health than with the results of physical fitness tests. The results of physical fitness tests were slightly more closely correlated with self-assessment of health than selfassessment of physical fitness. Self-assessment of health was found to be higher when indicators of aerobic endurance and

Table 1. Correlations between self-assessments (of health, physical fitness, and satisfaction with health) vs. various objective indicators of health and physical fitne

\begin{tabular}{|c|c|c|c|c|}
\hline Group & Variable & $\begin{array}{l}\text { Self- } \\
\text { assessment } \\
\text { of health }\end{array}$ & $\begin{array}{l}\text { Self- } \\
\text { assessment } \\
\text { of physical } \\
\text { fitness }\end{array}$ & $\begin{array}{l}\text { Satisfac- } \\
\text { tion with } \\
\text { health }\end{array}$ \\
\hline \multirow{3}{*}{ Health } & Chronic illnesses & $-0.195^{*}$ & $-0.244^{* *}$ & $-0.248^{* *}$ \\
\hline & Regular medication & $-0.324^{* * *}$ & $-0.215^{\star *}$ & -0.115 \\
\hline & Depression & $-0.333^{* * *}$ & $-0.319 * * *$ & $-0.197^{*}$ \\
\hline \multirow{12}{*}{$\begin{array}{l}\text { Physical } \\
\text { fitness }\end{array}$} & Left hand strength & 0.053 & 0.116 & -0.084 \\
\hline & Right hand strength & 0.118 & $0.173^{t}$ & -0.020 \\
\hline & Balance (left leg, eyes open) & -0.034 & 0.056 & 0.103 \\
\hline & Balance (right leg, eyes open) & -0.039 & 0.042 & 0.035 \\
\hline & Balance (left leg, eyes closed) & $0.205^{*}$ & 0.115 & 0.079 \\
\hline & $\begin{array}{l}\text { Balance (right leg, eyes } \\
\text { closed) }\end{array}$ & 0.033 & -0.017 & 0.008 \\
\hline & Aerobic endurance (stepping) & $0.237^{* *}$ & 0.087 & 0.072 \\
\hline & Flexibility (sit-and-reach) & 0.040 & $0.233^{* *}$ & 0.098 \\
\hline & Upper body mobility (left arm) & 0.058 & 0.114 & 0.173 \\
\hline & $\begin{array}{l}\text { Upper body mobility (right } \\
\text { arm) }\end{array}$ & 0.106 & 0.120 & 0.1328 \\
\hline & Lower body strength (chair) & $0.212^{*}$ & $0.204^{*}$ & -0.037 \\
\hline & Agility (up-and-walk) & 0.030 & 0.048 & 0.068 \\
\hline
\end{tabular}

${ }^{* * *}=\mathrm{p}<0.001 ;{ }^{* *}=\mathrm{p}<0.01 ;{ }^{*}=\mathrm{p}<0.05$. lower body strength as well as one of the balance indicators were higher. Self-assessment of physical fitness, in turn, was positively correlated with results for flexibility, lower body strength, and right hand strength (on a tendency level). No correlation was found between the results of fitness tests and self-assessments of satisfaction with health.

Table 2 shows correlation coefficients between selfassessments and two variables treated as determinants of health and physical fitness, that is age and financial situation. Selfassessment of physical fitness was found to be negatively correlated with age, while satisfaction with health was positively correlated with financial situation. Self-assessment of health was not found to be correlated with either of the two factors.

Table 2. Correlations between self-assessments (of health, physical fitness, and satisfaction with health) vs. determinants of health and physical fitness

\begin{tabular}{|c|c|c|c|}
\hline Variable & $\begin{array}{c}\text { Self-assessment } \\
\text { of health }\end{array}$ & $\begin{array}{c}\text { Self-assessment } \\
\text { of physical fitness }\end{array}$ & $\begin{array}{c}\text { Satisfaction } \\
\text { with health }\end{array}$ \\
\hline Age & -0.118 & $-\mathbf{0 . 1 8 6}$ & 0.090 \\
\hline Financial situation & -0.081 & -0.119 & $0.291^{* * *}$ \\
\hline
\end{tabular}

${ }^{* * *}=\mathrm{p}<0.001 ; \mathrm{t}=\mathrm{p}<0.1$.

Next, Table 3 shows the correlation coefficients for variables considered potential modifiers of self-assessment. Perception unreliability (number of errors) was found to be positively correlated with self-assessment of health and physical fitness; speed of observation was also positively correlated with self-assessment of fitness. Education was negatively correlated with self-assessment of physical fitness and satisfaction with health. The most significant relationships were found for selfassessment of physical fitness. None of the self-assessments were found to be correlated with mood.

Table 3. Correlations between self-assessments (health, physical fitness, and satisfaction with health) vs. variables potentially modifying such self-assessments

\begin{tabular}{|l|c|c|c|}
\hline \multicolumn{1}{|c|}{ Variable } & $\begin{array}{c}\text { Self-assessment } \\
\text { of health }\end{array}$ & $\begin{array}{c}\text { Self-assessment } \\
\text { of physical fitness }\end{array}$ & $\begin{array}{c}\text { Satisfaction } \\
\text { with health }\end{array}$ \\
\hline Education & -0.125 & $-\mathbf{0 . 2 1 2 ^ { * }}$ & $-\mathbf{0 . 2 5 2 ^ { * * * }}$ \\
\hline $\begin{array}{l}\text { Speed of } \\
\text { observation }\end{array}$ & 0.161 & $\mathbf{0 . 2 2 1 ^ { * }}$ & 0.093 \\
\hline $\begin{array}{l}\text { Unreliability of } \\
\text { perception }\end{array}$ & $\mathbf{0 . 2 0 3 ^ { * }}$ & $\mathbf{0 . 1 8 6 ^ { * }}$ & 0.021 \\
\hline $\begin{array}{l}\text { Unreliability of } \\
\text { attention }\end{array}$ & 0.017 & 0.097 & 0.008 \\
\hline Hedonic tone & 0.148 & 0.078 & -0.027 \\
\hline Energetic arousal & 0.057 & 0.123 & -0.079 \\
\hline Tension arousal & -0.061 & -0.026 & -0.046 \\
\hline
\end{tabular}

${ }^{* * *}=\mathrm{p}<0.001 ;{ }^{*}=\mathrm{p}<0.05$

In order to determine predictors of self-assessment of health, physical fitness, and satisfaction with health, we performed regression analysis using the following factors: objective indicators of physical health (chronic illnesses and regular medication use), mental health (depression) and physical fitness, determinant factors (age and financial situation), and modifying factors (education, perceptive fitness, and mood).

The groups of factors included in this study were found to predict the self-assessment of health only to a low degree 
(3-10\%). The most significant objective health indicators were regular medication use, aerobic endurance, and depression, the latter being the strongest predictor of health. Age and financial situation were not found to be significant in predicting selfassessment of health. Unreliability of perception, in turn, was found to be a significant negative predictor of self-assessment. Participants who had no symptoms of depression, did not take regular medication, had high aerobic endurance, and made higher numbers of errors in the perception test assessed their health more highly.

Table 4. Predictors of self-assessment of health

\begin{tabular}{|c|l|c|c|}
\hline $\begin{array}{c}\text { Group of } \\
\text { factors }\end{array}$ & \multicolumn{1}{|c|}{ Predictor } & Beta & Model $\left(\mathbf{R}^{2} ; \mathrm{F} ; \mathrm{p}\right)$ \\
\hline \multirow{2}{*}{$\begin{array}{c}\text { Objective } \\
\text { factors }\end{array}$} & Regular medication & -0.323 & $0.084 ; 5.016,0.030$ \\
\cline { 2 - 4 } & Depression & -0.333 & $\mathbf{0 . 1 0 3 ; 1 4 . 7 2 4 ; < 0 . 0 0 1}$ \\
\cline { 2 - 4 } & Aerobic endurance & 0.222 & $0.039 ; 4.965 ; 0.028$ \\
\hline Modifiers & Unreliability of perception & 0.203 & $0.031 ; 5.953 ; 0.050$ \\
\hline
\end{tabular}

For self-assessment of physical fitness, the value of $\mathrm{R}^{2}$ was below $10 \%$ in all cases. Depression was found to be a stronger predictor than flexibility in terms of objective factors. Speed of perception was also found to be a positive predictor of selfassessment of physical fitness. We found that respondents who did not suffer from depression, were flexible, and had high perception speeds assessed their physical fitness highly.

Table 5. Predictors of self-assessment of physical fitness ("thermometer" scale)

\begin{tabular}{|c|l|c|c|}
\hline $\begin{array}{c}\text { Group of } \\
\text { factors }\end{array}$ & \multicolumn{1}{|c|}{ Predictor } & Beta & Model $\left(\mathbf{R}^{2} ; \mathrm{F} ; \mathrm{p}\right)$ \\
\hline $\begin{array}{c}\text { Objective } \\
\text { factors }\end{array}$ & Flexibility & 0.225 & $0.041 ; 5.112 ; 0.026$ \\
\cline { 2 - 4 } & Depression & -0.319 & $\mathbf{0 . 0 9 4 ;} 13.435 ;<0.001$ \\
\hline Modifiers & Speed of perception & 0.221 & $0.038 ; 4.673 ; 0.032$ \\
\hline
\end{tabular}

The only objective factor found to be predictive of satisfaction with health was aggravated symptoms of depression. However, the strongest predictor was in fact education - one of the modifiers. Satisfaction with health was also correlated with financial situation. We found higher self-assessments of satisfaction with health in participants with lower education, better financial situations, and no symptoms of depression. Mood was not found to be a predictor of any of the variables.

Table 6. Predictors of satisfaction with health (WHOQOL)

\begin{tabular}{|c|l|c|c|}
\hline $\begin{array}{c}\text { Group of } \\
\text { factors }\end{array}$ & \multicolumn{1}{|c|}{ Predictor } & Beta & Model $\left(\mathbf{R}^{2} ; \mathrm{F} ; \mathrm{p}\right)$ \\
\hline $\begin{array}{c}\text { Objective } \\
\text { factors }\end{array}$ & Depression & -0.197 & $0.031 ; 5.193 ; 0.024$ \\
\hline Determinants & Financial situation & 0.291 & $0.069 ; 5.367 ; 0.024$ \\
\hline Modifiers & Education & -0.328 & $\mathbf{0 . 0 8 8} ; 5433 ; 0.024$ \\
\hline
\end{tabular}

\section{Discussion}

In general, participants in our study assessed their health highly and were satisfied with it; they also assessed their physical fitness highly. The results of self-assessment of health were found to be similar to those found in other studies involving physically active seniors $[1,6,8]$; they were also higher than those for seniors who are not physically active $[6,11,12,13,14]$. Such differences are generally interpreted as evidence of the influence of physical activity on self-assessment of health.

High self-assessment of physical fitness seems justified by the fact that a significant majority of the participants in our study regularly attended fitness classes held as part of the U3A programme. The close relationship between self-assessment of health and physical fitness can be interpreted as an argument supporting a two-way relationship between health and fitness. It is somewhat surprising that self-assessment of health was found to be less closely correlated with satisfaction with health than with self-assessment of physical fitness, while satisfaction with health was as closely correlated with self-assessment of health as with physical fitness. It is possible that this is at least partially due to our use of visual scales (vertical "thermometer") for assessing health and physical fitness as opposed to ordinal scales with marked and described points for assessing satisfaction with health.

Regarding the correlates of self-assessment of health, interestingly, our findings did not show links between self-assessment and factors that we had defined as determinants of health (age and financial situation), which were noted in previous studies $[6,11,12,13,14]$. This may be because the participants in our study were U3A students, which made our sample more uniform in terms of self-assessment of health than in terms of actual health. People who do not perceive themselves as healthy tend not to engage in physical exercise and other activities requiring leaving the home. Although age was correlated with self-assessment of physical fitness, which is due to a general worsening of health with increasing age, even this relationship was weak.

The group was also uniform in terms of place of residence (Warsaw) and relatively uniform in terms of financial status; therefore, the significance of financial status as a factor affecting access to healthcare was low. Nevertheless, financial situation was found to be a correlate and predictor of satisfaction with health. It appears that rather than reflecting the actual influence of financial situation on satisfaction with health, these relationships are the result of other factors. On one hand, financial situation is correlated with general satisfaction with life and happiness, while, on the other, self-assessment of financial situation and satisfaction with health may be affected by other variables not included in the study, in particular personality traits such as optimism [21, 22].

Self-assessment of health was found to be closely correlated with factors we had defined as objective indicators of health, both physical (chronic illnesses and regular medication use) and mental (aggravated symptoms of depression). This suggests that our participants' self-assessment was to some extent focused on somatic and mental symptoms. Aggravated symptoms are especially important here. Despite the low significance of the depression indicator and a low percentage of participants displaying symptoms of the disorder $(6 \%)$, it was correlated and could be used to predict all the variables (self-assessment of health, satisfaction with health, and self-assessment of physical fitness). Depression presents as a feeling of sadness, melancholy, and numbness, loss of ability to enjoy life (anhedonia), and a general feeling of malaise. In certain cases, depression causes 
or aggravates somatic disorders, such as headaches or tension around the neck and the back of the head, which can go as far as masking the underlying condition. As such, symptoms of depression are strong indicators of self-assessment of health. Low mood has a significant effect on modifying or even disturbing cognitive processes such as attention, perception, memory, and thinking [23]. People living with depression can be described as viewing the world in a negative way, which undoubtedly lowers their assessment of their health and fitness. Depression affects self-assessment of health and physical fitness in a range of ways.

Associations with objective indicators of physical fitness were found to be weaker. The fact that self-assessment of health was found to be positively correlated with aerobic endurance, lower body strength, and balance suggests that older women who are physically active perceive their physical fitness as an important element of their health and its assessment. It should be noted that other motor functions (flexibility and hand grip strength) was also found to be linked with self-assessment of physical fitness. Regression analysis confirmed the relationships described above. The results suggest that flexibility and strength are generally perceived as linked with physical fitness, while endurance is seen as a sign of health.

Finally, we examined the factors we had defined as modifiers of self-assessment. Relationships with education are particularly notable here. In contrast to previous studies [12, 13, 24], we did not find links between education and self-assessment of health; however, we did find an inversely proportional link between self-assessment of physical fitness and satisfaction with health. Education was also a negative (and indeed the strongest) predictor of satisfaction. The higher the education level of our participants was, the lower their self-assessment of their physical health and satisfaction with health was. This can be interpreted by assuming that individuals with a higher level of education are more aware of the significance of physical fitness and set themselves higher requirements, which means they have a tendency to view their fitness less highly. Their expectations of their health are also likely to be significantly higher.

The relationships between unreliability of perception and self-assessment of health and physical fitness were also notable. They were found to be positive in that the more errors a participant made, the higher their self-assessment of health and fitness was. Frequent mistakes can indicate perception difficulties, which may result from general cognitive deficits making it difficult for people to assess their attributes, typical in older age [25]. It should be noted that speed of perception is also positively correlated with self-assessment of physical fitness. Our other research found a positive correlation between the indicators of perception ability and the results of certain tests of physical fitness (balance, lower body strength, and aerobic endurance) [26, 27]. Older women who are physically fitter also have higher perception speeds. As such, this relationship should be viewed as evidence of accuracy in self-assessment of physical fitness in our participants, rather than a modifying effect of cognitive factors.

It should be noted that self-assessment of health and physical fitness was found to be independent of mood. It is difficult to say whether this is a general rule or something specific to our sample of female U3A participants. Further research is needed before any more concrete conclusions can be drawn.

In summary, our analysis confirms that self-assessment is a moderately accurate indicator of general health and physical fitness of elderly people. They are indeed linked with more objective indicators of health/illness and physical fitness, though they remain under the influence of modifying factors, in particular those in the cognitive sphere.
In closing, we should note that care should be taken when drawing more general conclusions from our results for several reasons. One is that our group was relatively small and uniform in terms of demographics. The participants were all women who attended U3A classes at the University of Physical Education in Warsaw, which means that they were by definition mentally and physically active and relatively healthy. This makes it difficult to generalise our research. Moreover, the correlative model of our study makes it impossible to formulate any cause-and-effect conclusions.

\section{Acknowledgements}

This study was carried out at the Józef Piłsudski University of Physical Education in Warsaw under research project DS. 191, which was financed by the Polish Ministry of Science and Higher Education. All the tests were conducted in the Laboratory for Research Development at the University of Physical Education in Warsaw. We would like to thank very much all the students of the University of the Third Age of the University of Physical Education in Warsaw for participating in the study.

\section{Literature}

1. Ćwirlej-Sozańska A. (2014). Physical activity and health status of the elderly. Przeglad Medyczny Uniwersytetu Rzeszowskiego i Narodowego Instytutu Leków w Warszawie 2, 173-181.

2. Zdziebło K. (2008). Modern demographic phenomena and the health problems of an ageing society. Studia Medyczne 9, 63-69. [in Polish]

3. Izdebski P., Polak A. (2005). Perceived life success and sense of coherence in elderly individuals as related to their current life status. Gerontologia Polska 13, 188-194. [in Polish]

4. Karczewski J.K. (ed.) (2002). Hygiene. Lublin: Wyd. Czelej. [in Polish]

5. Wiszomirska I., Krynicki B., Kaczmarczyk K., Gajewski J. (2015). The impact of functional training on postural stability and body composition in women over 60. Journal of Sports Medicine and Physical Fitness 55(6), 654-62.

6. Knapik A., Rottermund J., Myśliwiec A., Plinta R., Gruca M. (2011). Physical activity and self-evaluation of health in the elderly. Przegląd Medyczny Uniwersytetu Rzeszowskiego i Narodowego Instytutu Leków w Warszawie 2, 195-204. [in Polish]

7. Statistics Poland (GUS). (2012). Population Forecast for 2018-2035. Retrieved on December 5 th , 2012, from http:// www.stat.gov.pl/cps/rde/xbcr/gus/PUBL_L_prognoza_ludnosci_na_lata2008_2035.pdf. [in Polish]

8. Gębska-Kuczerowska A. (2002). Evaluating the correlation between active lifestyle and state of health in the elderly. Przegląd Epidemiologiczny 56, 471-477. [in Polish]

9. Knapik A., Saulicz E., Plinta R., Miętkiewicz-Ciepły E. (2005). The impact of systematic motor activity on spinal functionality based on tri-planar flexibility range measurements. Annales Academiae Medicae Silesiensis 59, 476-480. [in Polish]

10. Kozieł D., Trafiałek K. (2007). University of the Third Age attendance and quality of life in seniors. Gerontologia Polska 15, 104-108. [in Polish]

11. Gajewska O., Bryła M., Maniecka-Bryła M. (2012). Selfevaluation of the health of University of the Third Age attendees. Hygeia Public Health 47, 453-459. [in Polish] 
12. Jopkiewicz A. (2014). Self-evaluation of health, quality of life, and ability to cope in the elderly. Rocznik Lubuski 40, 261-273. [in Polish]

13. Nowicki G.J., Młynarska M., Ślusarska B., Korecka R., Kotus M. (2016). Self-evaluation of health and selected contributing factors in a group of basic health care patients over 65. Journal of Education, Health and Sport 6, 447-457. [in Polish]

14. Świtała M. (2009). Self-evaluation of health and its impact on the behaviour of elderly consumers. Gerontologia Polska 17, 129-136. [in Polish]

15. Stuart-Hamilton I. (2012). The Psychology of Ageing: An Introduction (5 $5^{\text {th }}$ ed.). London: Jessica Kingsley Publishers.

16. Matthews G., Wells A. (1999). The cognitive science of attention and emotion. In T. Dalgleish, M.J. Power (eds), Handbook of cognition and emotion. New York: Wiley.

17. Łosiak W. (2007). Psychology of emotion. Warsaw: Wydawnictwa Akademickie i Profesjonalne. [in Polish]

18. Grodzicki T., Kocemba J., Skalska A. (2006). Geriatrics with elements of general gerontology. Gdańsk: Via Medica. [in Polish]

19. Ciechanowicz A., Stańczak J. (2006). Tests of Attention and Perception - A handbook. Warsaw: Pracownia Testów Psychologicznych. [in Polish]

20. Goryńska E. (2005). The UWIST Mood Adjective Checklist (UMACL) of Matthews, Chamberlain and Jones - A handbook. Warsaw: Pracownia Testów Psychologicznych PTP. [in Polish]
21. Czapiński J. (2004). Psychological theories of happiness. In J. Czapiński (ed.), Positive psychology. The science of happiness, health, strength, and virtue (pp. 51-101). Warsaw: PWN. [in Polish]

22. Diener E., Lucas R.E., Oishi S. (2005). Subjective wellbeing: The science of happiness and life satisfaction. In C.R. Snyder, S.J. Lopez (eds), Handbook of positive psychology (2nd ed.) (pp. 63-73). New York: Oxford University Press.

23. Cierpiałkowska L. (2009). Psychopathology. Warsaw: Scholar. [in Polish]

24. Knapik A., Plinta R., Saulicz E., Gnat R. (2005). Impact of motor activity on the level and distribution of fat tissue and fitness of middle-aged men. Annales UMCS 16, 438-442. [in Polish]

25. Meisner B.A., Weir P.L., Baker J. (2013). The relationship between aging expectations and various modes of physical activity among aging adults. Psychology of Sport and Exercise 14, 569-576.

26. Piotrowska J., Guszkowska M., Kozdroń E., Niedzielska E., Leś A., Krynicki B. (2016). Perceptive ability of female students of the University of the Third Age and its links with physical fitness and mood. Baltic Journal of Health and Physical Activity 8(4), 136-146.

27. Wadsworth M., Butterworth S.L., Hardy R.J., Kuh D.J., Richards M., Langenberg C. et al. (2003). The life course perspective design: An example of benefits and problems associated with study of longevity. Social Science $\mathcal{E}$ Medicine 57, 2193-205.

Submitted: October 1, 2018

Accepted: December 17, 2018 